\title{
Modeling and Analyzing the Mean and Volatility Relationship between Electricity Price Returns and Fuel Market Returns
}

\author{
Ching-Chun Wei ${ }^{1}$ \\ ${ }^{1}$ Department of Finance, Providence University, Taichung City, Taiwan \\ Correspondence: Ching-Chun Wei, Department of Finance, Providence University, 200, Sec. 7, Taiwan \\ Boulevard, Shalu District., Taichung City, 43301, Taiwan. Tel: 886-4-2632-8001 Ext. 13603. E-mail: \\ ccw@pu.edu.tw
}

Received: March 31, 2016

Accepted: April 26, 2016

Online Published: June 25, 2016

doi:10.5539/ijef.v8n7p55

URL: http://dx.doi.org/10.5539/ijef.v8n7p55

\begin{abstract}
This paper has two objectives. First, we apply the symmetric and asymmetric VAR(1)-BEKK-MGARCH(1.1), VAR(1)-CCC-MGARCH(1,1), VAR(1)-DCC-MGARCH, VAR(1)-VARMA-CCC-MGARCH and VAR(1)VARMA-DCC-MGARCH models to explore the return and volatility interactions among electricity and other fuel price markets(oil, natural gas, and coal). Second, this paper investigates the importance of not only volatility spillover among energy markets, but also the asymmetric effects of negative and positive shockson the conditional variance of modeling one energy market's volatility upon the returns of future prices within and across other energy markets. The empirical results display that these models do capture the dynamic structure of the return interactions and volatility spillovers and exhibit statistical significance for own past mean and volatility short-and long-run persistence effects, while there are just a few cross-market effects for each model.
\end{abstract}

Keywords: return and volatility spillover, electricity market, fuel market, energy market, MGARCH

\section{Introduction}

The uncertain context that currently affects the world economy and the energy sector, as well as the unstable political situation of some countries that are the most important producers of raw materials (for example, oil, natural gas, coal, and electricity), makes it even more necessary to develop quantitative tools and models that help to improve investment decisions and to adequately deal with such increasing uncertainty. The risks to the energy sector are mainly linked with the high volatility of natural gas, coal, oil, and electricity prices, which evolve over time and aredifficult to model. Electricity is traded nowdays in competitive markets, as occurs with other commodities, but it presents some characteristics that make it quite different, such as it cannot be stored, or cannot be used for just a small amount, or demand needs to be covered immediately. These peculiar features are responsible for its highly volatilite behavior and the difficulty in its price forecasting. Other energy prices (such as oil, coal, and gas) are also very volatilite and difficult to forecast and model, yet they influence electricity prices as well.

Natural gas iswidely considered as a timely alternative source to oil, as stated by Munoz and Dickey (2009) in which natural gas is the main component of electricity generation and of electricity price. The inputs to electricity generation, such as oil and natural gas price changes, are directly or indirectly reflected in electricity price changes. These fuel prices may also affect electricity prices to the extent that they serve as substitutes on the demand side of the energy market. Mohanmadi (2009) stated that under market-based pricing, electricity prices should partly reflect fuel costs at least in the long run, but under cost-based pricing, they should reflect a mark-up over average or marginal costs.

The relationship between electricity prices and fuel costs has been extensively studied in the previous literatures. For example, Emery and Liu (2002) analyzed the relationship between electricity and natural gas future prices on the New York Mercantile Exchange (NYMEX), California Oregon Border (COB), and Palo Verde (PU) and found that the two futures prices are cointegrated. Mjelde and Bessler (2009) examined the relationships among electricity prices and coal, natural gas, crude oil, and uranium prices. Empirical results show that peak electricity prices react to shocks in natural gas prices. Serletis and Shahmoradi (2006) investigated the causal relationships between natural gas and electricity price (and volatility) changes, with results indicatingbi-directional (linear and non-linear) causality between them. Mohammadi (2009) looked at the long-run and short-run dynamic relations 
among electricity prices and coal, natural gas, and crude oil prices in the U.S. marketfrom 1960 to 2007. He found significant long-run relationship between electricity and coal prices and uni-directional short-run causality relation from coal and natural gas prices to electricity prices.Furio and Chulia (2012) used VECM and MGARCH methods to study the causal relationship between Spain's electricity, oil, and natural gas prices. They found that oil and natural gas forward prices play a important role in electricity prices. Moreover, causation, both in price and volatility, runs from oil and natural gas forward markets to electricity forward markets at Spain.

The important characteristic of electricity is that it cannot be stored at any significant scale. The lack of inventories together with the fact that power generation and consumption need to be coincident with each other means prices react quickly to supply and / or demand disruptions. As a consequence, spot prices for electricity are highly volatile. According to this context, forward markets play a major role to the extent they provide a tool for participants to manage the risk derived from the volatility of spot prices. Thereby, hedging helps prevent financial difficulties following adverse price movements, which can have a positive effect on the financial stability of utilities for traders that use forward markets to protect their spot positions. Another important function of forward markets lies in price discovery.Electricity spot prices cannot be used to make meaningful predictions about movements in the forward price. Instead, a more fitting theory for electricity markets is provided by the Unbiased Expectation Hypothesis, which mainly states that forward prices are unbiased predictors of future spot prices, specifically for these that will be observed during the maturity periods of the forward contracts.

Explicitly modeling the volatility process of electricity prices for daily or higher frequencies has also gained much attention by researchers, bringing about a growing field in the recent empirical literature. Autoregressive integrated moving average (ARIMA) models with autoregressive conditional heteroskedastic (ARCH) (Engle, 1982) or generalized autoregressive conditional heteroskedastic (GARCH) (Bollerslev, 1986) processes are the more widely used approaches for modeling the mean and volatility of electricity prices. The success of the GARCH model has subsequently led to a family of univariate and multivariate GARCH models that capture different behaviors of price returns, including time-varying volatility, persistence and clustering of volatility, and the asymmetric effects of positive and negative shocks of equal magnitude. Substantial research has been conducted on spillover effects in energy future markets. Lin and Tamvakis (2001) investigated volatility spillover effects between the New York Mercantile Exchange (NYMEX) and International Petroleum Exchange (IPE), with crude oil empirical results exhibitinga substantial spillover effect. Ewing et al. (2002) investigated the transmission of volatility between oil and natural gas markets using daily return data and found that changes in volatility in one market may have spillovers to the other market. Chang et al. (2009) looked at multivariate conditional volatility and conditional correlation models of the spot, forward, and future price returnsof three crude oil markets (Brent, WTI, and Dubai) and provided evidence of significant volatility spillovers andasymmetric effects in the conditional volatilities across returns for each market.Guesmi and Fattoum (2014) used DCC-AGARCH models to estimate dynamic conditional correlations between oil importing countries and oil exporting countries. They found that cross-market co-movement, as measured by conditional correlation coefficients, increases positively in response to significant aggregate demand.

Linza et al. (2006) applied the constant conditional correlation (CCC) model of Bollerslev (1990) and the DCC model of Engle (2002) for West Texas Intermediate (WTI) oil forward and future returns.Manera et al.(2006) employed the CCC and the Vector Autoregressive Moving(VARMA-GARCH) models of Ling and McAleer (2003), the VARMA-Asymmetric GARCH (VARMA-AGARCH) model of McAleer et al. (2009), and the DCC model upon spot and forward returns in the Tapis crude oilmarket.Da Veiga et al. (2008) analyzed the multivariate Vector ARMA-GARCH (VARMA-GARCH) model of Ling and McAleer (2003) and the VARMA-AGARCH model of McAleer et al. (2009) and found that they are superior to the GARCH model of Bollerslev (1986) and the GJR model of Glosten et al. (1992).

There are two objectives of this paper. First, we apply the $\operatorname{VAR}(1)-B E K K-M G A R C H(1,1)$, VAR(1)-CCC-MGARCH(1,1), VAR(1)-DCC-MGARCH(1.1)， VAR(1)-VARMA-CCC-MGARCH(1.1) and VAR(1)-VARMA-DCC-MGARCH(1.1) models to analyze the return and volatility interactions among electricity and other fuel price markets (oil, natural gas, and coal). These models cansimultaneously estimate returns and volatility cross-effects for the fuel price markets under consideration. The MGARCH approach further explains the origins, directions, and transmission intensity of the shocks between markets. All these models can capture the effects on the current conditional volatility of own innovations and lagged volatility as well as the cross-market shocks and the volatility transmission of other markets. As shown by Gallaghar and Twomey (1998), modeling price volatility spillover provides better insight into the dynamic price relationship between markets, but inferences about any inter-relationship depend importantly on how we model the cross 
dynamics in the conditional volatilities of the markets. Second, this paper investigates the importance of not only volatility spillover among energy markets, but also the asymmetric effects of negative and positive shocks of equal magnitude on the conditional variance of modeling one energy market's volatility upon the returns of future prices within and across other energy markets. We do this by using the VAR(1)-BEKK-AMGARCH(1.1), VAR(1)-CCC-AMGARCH(1.1), VAR(1)-DCC-AMGARCH(1.1), VARMA-CCC-AMGARCH(1.1), and VARMA-DCC-AMGARCH(1.1) models.

The structure of the remainder of this paper is organized as follows. Section 2 discusses the multivariate GARCH model to be estimated. Section 3 describes the data and some preliminary analysis. Section 4 analyzes the empirical estimates from the empirical model. Concluding remarks are given in Section 5.

\section{Econometric Models}

The objective of this study is to investigate the price returns and volatility spillovers between electricity and fuel price markets. First proposed by Bollerslev et al. (1988), the MGARCH models are becoming standard in finance and energy economics. Combined with a Vector Autoregressive model for the mean equation, theyallow for rich dynamics in the variance-covariance structure of the series, making it possible to model spillovers in both the values and conditional variances of series under this study.

This section presents the BEKK model of Engle and Kroner (1995), the CCC model of Bollerslev (1990), the VARMA-AGARCH model of McAleer et al. (2009), and the VARMA-GARCH model of Ling and McAleer (2003). These models assume constant conditional correlations and do not suffer from the problem of dimensionality, as compared with the VECH model (McAleer et al., 2008; Caporin \& McAleer, 2009; Chang et al., 2013). The BEKK model is a more general specification, while the DCC model of Engle (2002) is less computationally demanding and enables time-varying correlation among series with only two additional parameters (Efimova, 2014).

MGARCH is a valuable approach, because volatility spillovers are expected among coal, oil, natural gas, and electricity markets. Not only are they substitutes in consumption, but coal, natural gas, and oil are also used as inputs in electricity generation, and oil, natural gas, and coal are complements in production. The chosen specification allows us to model the transmission of price volatility transmission from one energy market to the others and to estimate the effects of volatility in any of the four energy markets on the price of each energy market.

The VARMA method to modeling the conditional variances allows large shocks to one variable to affect the variance of other variables. It is a convenient specification that allows for volatility spillovers. This specification assumes symmetry in that positive shocks and negative shocks of equal magnitude have the same impact on conditional volatility. McAleer et al. (2009) extended the VARMA-GARCH model to include asymmetric GARCH effects, and this is referred to as the VARMA-AGARCH model.

\subsection{VAR(1) Conditional Mean Model}

For the empirical analysis of energy price mean return spillovers, this paper assumes that the conditional mean of price returns on the electricity and fuel markets can be described as a Vector Autoregressive (VAR) model. Under the four-variable model, we describe the VAR(1) model as:

$$
\begin{aligned}
& r_{e}=\alpha_{e}+\beta_{e 0} r_{e, t-1}+\beta_{e 1} r_{o, t-1}+\beta_{e 2} r^{\prime}{ }_{s, t-1}+\beta_{e 3} r_{e, t-1}+\varepsilon_{e t} \\
& r_{o}=\alpha_{o}+\beta_{o 0} r_{e, t-1}+\beta_{o 1} r_{o, t-1}+\beta_{o 2} r_{s, t-1}^{\prime}+\beta_{o 3} r_{e, t-1}+\varepsilon_{o t} \\
& r_{s}=\alpha_{s}+\beta_{s 0} r_{e, t-1}+\beta_{s 1} r_{o, t-1}+\beta_{s 2} r^{\prime}{ }_{s, t-1}+\beta_{s 3} r_{e, t-1}+\varepsilon_{s t} \\
& r_{c}=\alpha_{c}+\beta_{c 0} r_{e, t-1}+\beta_{c 1} r_{o, t-1}+\beta_{c 2} r_{s, t-1}^{\prime}+\beta_{c 3} r_{e, t-1}+\varepsilon_{c t}
\end{aligned}
$$

Here, $r_{e}, r_{o}, r_{s}$, and $r_{c}$ are the logarithmic returns of the electricity, oil, natural gas, and coal price return series, respectively. The residuals $\varepsilon_{e t}, \varepsilon_{o t}, \varepsilon_{s t}$, and $\varepsilon_{c t}$ are assumed to be serially uncorelated, but the covariance does not need to be zero. Here, the parameter coefficients $\left(\beta_{e 0}, \beta_{o 1}, \beta_{s 2}\right.$, and $\left.\beta_{c 3}\right)$ provide the measure of own mean price return spillovers. However, the rest of the parameter coefficients measure the cross-mean spillover between electricity prices and fuel energy markets.

\subsection{MGARCH Conditional Volatility Spillover Models}

This section presents the BEKK model of Engle and Kroner (1995), the CCC model of Bollerslev (1990), the DCC model of Engle (2002), the VARMA-GARCH model of Ling and McAleer (2003), and the VARMA-AGARCH model of McAleer et al. (2009). This paper employs the MGARCH approach to examine 
the price returns of inter-dependence and dynamic volatility spillover between electricity, oil, natural gas, and coal markets.

The first model contains a variance equation, which is the dynamic conditional model of BEKK introduced by Engle and Kroner (1995). The BEKK model of MAGRCH(1.1) is given as:

$$
H_{t}=C^{\prime} C+A^{\prime} H_{t-1} A+B^{\prime} \eta_{t-1} \eta^{\prime}{ }_{t-1} B
$$

Here, $C^{\prime} C, B^{\prime} B$, and $A^{\prime} A$ are $4 X 4$ matrices with $C$ being a triangular matrix to ensure positive definiteness of $H_{t}$. This specification allows positive volatilities $H_{t-1}$, as well as lagged values of $\eta_{t} \eta_{t}^{\prime}$, to show up in estimating the current energy price volatilities. We assume matrix $H_{t}$ is symmetric. Thus, the model provides eight unique equations modeling the dynamic variances of electricity, oil, gas, and coal prices, as well as the covariance between them.

According to this diagonal representation, the conditional variances are functions of their own lagged values and own lagged square return shocks, while the conditional covariances are functions of the lagged covariance and lagged cross-products of the corresponding returns shocks. The estimations of the BEKK models are carried out by the quasi-maximum likelihood (QML), where the conditional distribution of error term is assumed to follow a joint Gaussian log-likelihood function of a sample of T observations and $K=4$ as follows:

$$
\log L=-\frac{1}{2} \sum_{t=1}^{T}\left[k \log (2 \pi)+\ln \left|H_{t}\right|+\eta_{t-1} H_{t}^{-1} \eta_{t}\right]
$$

We present the CCC model of Bollerslev (1990) as:

$$
R_{t=} E\left(R_{t} \mid \Psi_{t-1}\right)+\varepsilon_{t}, \varepsilon_{t}=D_{t} Q_{t}, \operatorname{Var}\left(\varepsilon_{t} \mid \Psi_{t-1}\right)=D_{t} \Gamma D_{t}
$$

Here, we denote $R_{t}=\left(R_{1 t} \ldots R_{m t}\right)^{\prime}, Q_{t}=\left(Q_{1 t} \ldots Q_{m t}\right)^{\prime}$ as a series of independently and identically distributed random vectors. These return series decompose $R$ into its predictable conditional mean and random component, where $\Psi_{t}$ is the past information available at time $t, D_{t}=\operatorname{diag}\left(h_{t^{\frac{1}{2}}} \ldots h_{m t^{\frac{1}{2}}}\right)$, and $m$ is the number of returns. As $\Gamma=E\left(D_{t} D^{\prime}{ }_{t} \mid \Psi_{t-1}\right)=E\left(D_{t} D_{t \prime}\right)$, where $\Gamma=e_{i j}=e_{j i}$ for $i_{j} j=1 \ldots m$, the constant conditional correlation matrix of the unconditional shocks, $Q_{t}$, is equal to the constant conditional covariance matrix of the conditional shocks, $\varepsilon_{t}$. The conditional covariance matrix is positive definite if and only if all the conditional variances are positive and $\Gamma$ is positive definite. Here, $\Gamma$ is equal to $D_{t}^{-1} \Omega D_{t}^{-1}$, which is assumed constant over time, and each conditional correlation coefficient is estimated from the standard residual of $\varepsilon_{t}$ (Chang et al., 2013).

The CCC model of Bollerslev (1990) assumes that the conditional variance of price returns, $H_{i t}, i=1 \ldots . m$, follows a univariate GARCH process defined as:

$$
H_{i t}=Z_{i}+\sum_{i=1}^{r} A_{i j} \sum_{i, t-j}^{2}+\sum_{j=1}^{3} B_{i j} h_{i, t-j}
$$

Here, $A_{i j}$ represents the ARCH effect and the short-run persistence of shocks to returni. However, $B_{i j}$ shows the GARCH effect, and $A_{i j}$ plus $B_{i j}$ denotes the long-run persistence of shocks to returns. In the DCC model, which assumes a time-dependent conditional correlation matrix $R_{t}=\left(e_{i j, t}\right), i, j=1 \ldots .4$, the conditional variance-covariance matrix $\mathrm{Ht}$ is defined as:

$$
H_{t}=D_{t} R_{t} D_{t}
$$

Here, $D_{t}=\operatorname{diag}\{\sqrt{\text { hit }}\}$ is a $4 \times 4$ diagonal matrix of time-varying standard deviations from univariate GARCH models, and $R_{\mathrm{t}}=\{e i j\}_{t}, i, j=1 \ldots 4$, which is a correlation matrix containing conditional correlation coefficients.

We define $H_{i t}$ as a $\operatorname{GARCH}(1,1)$ specification as follows:

$$
h_{i t}=w_{i}+\sum_{j=1}^{n} \alpha_{i t} \sum_{i j-n}^{2}+\sum_{t=1}^{k} B_{i l} h_{i t-l} \text { and } R_{t}=\operatorname{diag}\left(\sqrt{q_{i j, t}}\right) Q_{t} \operatorname{diag}\left(\sqrt{q_{i j, t}}\right)
$$

We now give the $4 \times 4$ symmetric positive definite matrix $Q_{t}=\left(q_{i j}\right)_{t, i, j}=1 \ldots 4$ by: 


$$
Q_{t}=(1-\alpha-\beta) \bar{Q}+\alpha \varepsilon_{t-1} \mathcal{E}_{t-1}^{\prime}+\beta Q_{t-1}
$$

Here, $Q_{t}$ is the $4 \times 4$ conditional covariance matrix $\bar{Q}$ obtained from the first stage of estimation and $Q_{t}^{*}$ is a diagonal matrix containing the square root of the diagonal elements of $Q_{t}$. The DCC-MGARCH process is estimated by using the maximum likelihood method in which the log-likelihood can be expressed as:

$$
L=\frac{-1}{2} \sum_{t=1}^{T}\left(n \log (2 \pi)+2 \log \left|D_{t}\right|+\log \left|R_{t}\right|+\varepsilon^{\prime}{ }_{t} R_{t}^{-1} \varepsilon_{t}\right)
$$

The estimation of DCC is broken into two stages, simplifying the estimation of a time-varying correlation matrix. In the first stage, univariate volatility parameters are estimated using GARCH models for each of the variables. In the second stage, the standardized residuals from the first stage are used as inputs to estimate a time-varying correlation matrix. The DCC model allows asymmetry, meaning that the weights are different for positive and negative changes to a series. The asymmetries are in variances, not in correlations (Cappielo et al., 2003).

This study also utilizes the DCC model form of the MEGARCH model to analyze the electricity market and fuel market interdependence and also the volatility transmission between electricity, gas, oil, and coal markets. The asymmetric GARCH model captures the asymmetric volatility spillovers and assumes that the correlations between shocks will be constant over time. Here, this study allows these correlations to be time-varying. Following Sarva et al. (2005), this paper sets up the VAR(1)-DCC-MGARCH $(1,1)$ model as:

$$
\begin{gathered}
R_{i t}=\beta_{i o}+\sum_{j=1}^{n} \beta_{i j} R_{j, t-1}+U_{i t} \\
\sigma_{i . t}^{2}=\exp \left[\alpha_{i o}+\sum_{j=1}^{n} \alpha_{i j} f_{j}\left(Z_{j, t-1}\right)+\delta_{i} \ln \left(\sigma_{i, t-1}^{2}\right)\right] \\
f_{j}\left(Z_{j, t-1}\right)=\left(\left|Z_{j, t-1}\right|-E\left(\left|Z_{j, t-1}\right|\right)+r_{j} Z_{j, t-1}\right)
\end{gathered}
$$

According to the mean equation, the dynamic return relationships among the energy markets are captured by using a $\operatorname{VAR}(1)$ model, $\mathrm{E}\left[R_{t} \mid U_{t-1}\right]$, where $U_{t-1}$ is the past information available at time $t-1$. Here, Rit is a function of own past returns and the cross-market price return, $R_{j, t-1}$. The parameter coefficient of $B_{i j}$ captures the return spillover relationships in different price markets, for $i \neq j$. The conditional variance in each market is an exponential function of past standardized innovations $\left(Z_{j, t-1}=\varepsilon_{j, t-1} \mid b_{j, t-1}\right)$. Persistence in volatility is measured by $\delta_{i}$. Suppose that $\delta_{i}=1$, and then the unconditional variance does not exist and the conditional variance follows an I(1) process. The coefficients of $\alpha_{i j}$ measure the spillover effects, while $\mathrm{r}_{j}<0$ implies asymmetry. The asymmetric influence of innovation on the conditional variance is captured by the term $\left(\sum_{j=1}^{n} \alpha_{i j} f_{j}\left(Z_{j, t-1}\right)\right)$. Here, a significant positive $i_{j}$ together with a negative(positive) $\mathrm{r}_{j}$ shows that negative shocks in market $j$ have a greater impact on the volatility of market $i$ than positive(negative) shocks. The ratio of $\left|-1+r_{j}\right| /\left(1+r_{j}\right) \mid$ measures the relative importance of the asymmetric (or leverage) effect.

The notations $\left(\left|Z_{j, t}\right|-E\left(\left|Z_{j, t-1}\right|\right)\right.$ measure the size effects, which show that a positive $\alpha_{i j}$ implies that the impact of $Z_{j, t}$ on $X, \sigma_{i, t}^{2}$ will be positive(negative) if the magnitude of $Z_{j, t}$ is greater than its expected value $E\left(\left|Z_{j, t}\right|\right)$. The distrubance error term of the mean equation is assumed to be conditionally multivariate normal with zero mean, and conditional covariance matrix $\mathrm{Ht}$ is given as:

$$
\varepsilon_{t} \mid \Psi_{t-1} \sim N\left(0, H_{t}\right), H_{t}=D_{t} S_{t} D_{t,} \sigma_{i j, t}=q_{i j, t} \sigma_{i, t} \sigma_{j t}
$$

In the above equation, $\mathrm{D}_{t}$ is a nxn diagonal matrix with the time-varying standard deviations of equation on the diagonal and $\mathrm{S}_{t}$ is a time-varying symmetric correlation matrix as:

$$
\mathrm{D}_{\mathrm{t}}=\left[\begin{array}{ccc}
\sigma_{1, \mathrm{t}} & 0 \ldots & 0 \\
0 & \mathrm{~b}_{2, \mathrm{t}} & 0 \\
\vdots & \ddots & \vdots \\
0 & 0 & \mathrm{~b}_{\mathrm{n}, \mathrm{t}}
\end{array}\right] \mathrm{S}_{\mathrm{t}}=\left[\begin{array}{ccc}
\mathrm{S}_{1,1, \mathrm{t}} & \mathrm{S}_{1,2, \mathrm{t}} \ldots & \mathrm{S}_{1, \mathrm{n}, \mathrm{t}} \\
\mathrm{S}_{2,1, \mathrm{t}} & \mathrm{S}_{2,2, \mathrm{t}} & \mathrm{S}_{2, \mathrm{n}, \mathrm{t}} \\
\vdots & \vdots & \vdots \\
\mathrm{S}_{\mathrm{n}, 1, \mathrm{t}} & \mathrm{S}_{\mathrm{n}, 2, \mathrm{t}} & \mathrm{S}_{\mathrm{n}, \mathrm{n}, \mathrm{t}}
\end{array}\right]
$$

The DCC model is a specification of the dynamic correlation matrix $S_{t}$. The dynamic correlations are captured in this model by the asymmetric general diagonal DCC equation: 


$$
Q_{t}=\left(\bar{Q}-A^{\prime \bar{Q}} A-B^{\prime \bar{Q}} B-C^{\prime \bar{N}} C\right)+A^{\prime Z_{t-1}, Z_{t-1}} A+B^{\prime Q_{t-1} B} B+C^{\prime \eta_{t-1} \eta_{t^{\prime}-1} C}
$$

Here, $\bar{Q}$ and $\bar{N}$ are the unconditional correlation matrices of $Z_{t}$ and $\eta_{t}$, with $\eta_{i, t}=I\left[Z_{i, t<0}\right] Z_{i, t}$, where $I\left[Z_{i, t<0}\right]$ is the indicator function that takes the value unity when $Z_{i, t<0}$ (Engle, 2002; Capiello et al., 2003). The matrices of $A, B$, and $C$ are restricted to being diagonal for estimation purposes. If $\left(\bar{Q}-A^{\prime} \bar{Q} A-B^{\prime} \bar{Q} B-C^{\prime} \bar{N} C\right)$ is positive definite, then $Q_{t}$ will be positive definite with probability one. Because $Q_{t}$ does not have unit diagonal elements, then we scale it to get a correlation. Matrices $S_{t}$ are given as $S_{t}=Q_{t *}-Q_{t} Q_{t *-1}$. However, the MEGARCH model allows us to test both the volatility spillovers and asymmetries, but it is not useful to apply this model to the conditional correlations, because it would unduly restrict the conditional correlations to be always positive and because it has to many parameters. The DCC model does not have these problems, but does allow for the possibility of asymmetric effects.

The model can be estimated by maximum likelihood, in which the log-likelihood function can be shown as:

$$
\begin{gathered}
L(Q)=-\frac{1}{2} \sum_{t=1}^{T}\left(k \log (2 \pi)+\log \left(\left|H_{t}\right|\right)+\varepsilon^{\prime}{ }_{t} H_{t}^{-1} \varepsilon_{t}\right. \\
=-\frac{1}{2} \sum_{t=1}^{T}\left(k \log (2 \pi)+\log \left(\left|D_{t} S_{t} D_{t}\right|\right)+{ }^{\prime}{ }_{t} D_{t}^{-1} S_{t}^{-1} D_{t}^{-1} \varepsilon_{t}\right)
\end{gathered}
$$

Here, $k$ is the number of equations, $T$ is the number of observation, $Q$ is the parameter vector to be estimated, $\varepsilon_{t}$ is the vector of innovations at time $\mathrm{t}$, and $H_{t}$ is the time-varying conditional variance-covariance matrix with diagonal elements and cross-diagonal elements. Although Engle (2002) and Cappiello et al. (2003) used the two-step approach, Wong and Vlaar (2003) showed this can lead to a relatively large loss of efficiency. This study employs the VAR(1)-MGARCH model by including the lagged returns from each market in the mean equation in order to capture the price spillover effects from one market to the other markets. Similarly, the variance equation captures the volatility spillover effects and also the asymmetry effects. We utilize the one-step estimation procedure, which is more efficient than the two-step approach.

\subsection{MGARCH-Asymmetric Model}

This study uses the daily price returns of the energy markets, which are computed as first differences of their natural logarithms. As the goal of this study is to consider the interdependence across the four energy markets, this study use the MGARCH model in the style of the BEKK model proposed by Engle and Kroner (1995). We first consider four-variate sequences of data $\left\{r_{t}\right\}_{t=1}^{n}$ consisting of electricity price changes and the other energy price market returns. The statistical model is given by:

$$
\gamma_{i, t}=\alpha_{i t}+\beta_{i t} \sum_{i=1}^{4} \gamma_{i, t-1}+\varepsilon_{i t}, \varepsilon_{i t}=\sqrt{H_{t}} V_{t}
$$

Here, $r_{i, t}$ is the $4 X 1$ vectors of the four daily energy price returns at time $t, \varepsilon_{t}$ is a $4 X 1$ vector of residuals, $V_{t}$ is a $4 X 1$ vector of standardized (i,i.d) residuals, and $H_{t}$ is the $4 X 4$ conditional variance-covariance matrix. The $4 X 1$ vector, $\alpha_{i t}$, represents a constant.

Bollerslev et al. (1988) proposed that $H_{t}$ is a linear function of the lagged squre errors, the cross products of errors, and the lagged values of elements of $H_{t}$ as follows:

$$
\operatorname{Vech}\left(H_{t}\right)=\operatorname{Vech}(C)+\sum_{i=1}^{n} A_{i} \operatorname{Vech}\left(\varepsilon_{t-i} \varepsilon^{\prime}{ }_{t-i}\right)+\sum_{i=1}^{T} G_{i} \operatorname{Vech}\left(H_{t-i}\right)
$$

Here, Vech is the operator that stacks the lower triangular portion of a symmetric matrix into a vector. The problems with this are that the number of parameters to be estimated is large and the restrictions on the parameters are to ensure that the conditional variance matrix is positive definite. Engle and Kroner (1995) proposed the BEKK model to overcome the above problem as: 


$$
H_{t}=G^{\prime} G+A^{\prime U^{\prime}}{ }^{-1} A+B^{\prime H_{t-1}} B
$$

The BEKK model provides cross-market effects in the variance-covariance equation and guarantees positive semi-definiteness by working with quadratic forms. The conditional variance-covariance matrix is specified according to the asymmetric BEKK model (ABEKK) of Kroner and $\mathrm{Ng}$ (1998). The ABEKK model allows the asymmetric response of volatility (i.e., price volatility tends to rise more in response to negative shocks (bad news) than to positive shocks (good news)) in the variance and co-variance:

$$
H_{t}=G^{\prime} G+A^{\prime} u_{t-1}^{\prime} u_{t-1} A+B^{\prime} H_{t-1} B+D^{\prime} \rho_{t-1}^{\prime} \rho D
$$

Here, $\rho_{t}$ is defined as $U_{t}$ if $U_{t}$ is negative and zero otherwise. The last part of the right-hand side for $H_{t}$ captures the asymmetric property of the time-varying variance-covariance. $G$ is a $4 \mathrm{X} 4$ lower triangular matrix of constants, while $A, B$, and $D$ are $4 X 4$ parameter matrices. The diagonal parametric in matrices $A$ and $B$ measures the effects of own past innovations and past volatility of market $i$ on its conditional variance, while the diagonal parameters in matrix $D$ measure the response of market $\mathrm{i}$ to its own past negative innovations. The off-diagonal parameters in matrices $A$ and $B$, measure the cross-market effects of stock and volatility, also known as volatility spillover, while the off-diagonal parameters measure the response of market $i$ to negative shocks, i.e., bad news, from the other markets. This is called the cross-market asymmetric response.

The BEKK models can be estimated efficiently and consistently using the full information maximum likelihood method. The log likelihood function of the joint distribution is the sum of all the log likelihood functions of the conditional distribution. The log likelihood function is given as:

$$
L_{t}=\frac{n}{2} \ln (2 \pi)-\frac{1}{2} \ln \left|H_{t}\right|-\frac{1}{2} u_{t} H_{t}^{-1} u_{t}
$$

This study takes the VARMA-GARCH model of Ling and McAleer (2003) and the VARMA-AGARCH model of McAleer et al. (2009) to set up the volatility dynamics and conditional correlations between electricity and fuel energy prices. The VARMA-AGARCH model is an extension of the VARMA-GARCH model of Ling and McAleer (2003) and assumes the symmetry in the effects of positive and negative shocks of equal magnitude on the conditional volatility. The VARMA-GARCH approach to modeling the conditional variance allows large shocks to one variable to affect the variances of the other variables. The VARMA-GARCH $(1,1)$ model used to model the time-varying variances and covariancesis:

$$
\begin{gathered}
\mathrm{R}_{i t}=\mathrm{E}\left(\mathrm{R}_{i t} \mid \mathrm{X}_{t-1}\right)+\mathrm{u}_{t} \\
\emptyset(L)\left(R_{t-u}\right)=\Psi(L) u_{t} \\
u_{t}=D_{t} \eta_{t} \\
H_{t}=A_{t}+\sum_{i=1}^{r} B_{i} \overrightarrow{u_{t-l}}+\sum_{j=1}^{s} C_{j} H_{t-j}
\end{gathered}
$$

Here, $\mathrm{R}_{i t}$ is the return for variable series $i$ at time $\mathrm{t}, \mathrm{X}_{t-1}$ is the past information available at time $\mathrm{t}$, $\emptyset_{L}=l_{m}-\emptyset_{1} l \ldots . \varnothing P L^{P}$ and $\Psi(L)=l_{m}-\Psi_{1 L} \ldots . .-\Psi_{q} L^{q}$ are polynomials in the lag operator, $\mathrm{H}_{t}=$ $\left(\mathrm{h}_{1 t} \ldots . . \mathrm{h}_{m t}\right), \eta_{t}=\left(\eta_{1 t}-\eta_{m t}\right)^{\prime}, A_{t}=\left(w_{1 t}-w_{m t}\right)^{\prime}, \bar{u}_{t}=\left(u_{i t}^{2}-u_{m t}^{2}\right)^{\prime} D_{t}$ is diag $\left(\mathrm{h}_{t} \frac{1}{2}\right), m$ is the returns to be analyzed, $t=1 \ldots m, B_{i}$ and $\mathrm{C}_{j}$ are $m x m$ matrices, and $\alpha_{i j}$ and $\beta_{i j}$ for $i, j=1 \ldots \mathrm{m}$ are $m X m$ matrices and represent the ARCH and GARCH effects, respectively. The spillover effects of the conditional variance between electricity price future returns and fuel energy price future returns are given in conditional volatility for each market in the portfolio. If $m=1$, then the VARMA-GARCH model reduces to the univariate GARCH model of Bollerslev (1986).

McAleer et al. (2008) proposed the VARMA-AGARCH model to accommodate asymmetric impacts of the positive and negative shocks and to capture asymmetric spillover effects from each of the other returns. The VARMA-AGARCH model specification of the conditional variance is:

$$
\mathrm{H}_{t}=\mathrm{A}_{t}+\sum_{i=1}^{r} B_{i} u_{t-i}+\sum_{i=1}^{r} D_{i}\left(I_{t-i}\right) \overrightarrow{u_{t-l}}+\sum_{j=1}^{s} C_{j} H_{t-j}
$$

Here, $\mathrm{u}_{i t}=\eta \mathrm{h}_{i t}^{1 / 2}$ for all $i$ and $t, D_{i}$ are $m x m$ matrices, and $\mathrm{D}_{i}\left(\mathrm{I}_{t-i}\right)$ is an indicator variable, such that: 


$$
\mathrm{I}=\left(\begin{array}{ll}
0, & u_{i t}>0 \\
1, & u_{i, t} \leq 0
\end{array}\right.
$$

If $D_{i}=0$ for all $i$, then VARMA-AGARCH reduces to VARMA-GARCH. Furthermore, if $D_{i}=0$, with $B_{i}$ and $C_{j}$ being diagonal matrices for all $i$, and $j$, then VARMA-AGARCH reduces to the CCC model of Bollerslev (1990). The CCC model does not have asymmetric effects of positive and negative shocks on conditional volatility and volatility spillover effects across different financial assets.

The parameters can be estimated by maximum likelihood by using a joint normal density as:

$$
\hat{Q}=\operatorname{argmin} \frac{1}{2} \sum_{t=1}^{n}\left(\log \left|Q_{t}\right|+u_{t}^{1} Q_{t}^{-1} u_{t}\right)
$$

Here, $\hat{Q}$ is the vector of parameters to be estimated by the conditional log-likelihood function. Moreover, $\left|Q_{t}\right|$ is the determinant of $Q_{t}$, the conditional covariance matrix, when $\eta_{t}$ does not follow a joint multivariate normal distribution. The Quasi-MLE (QMLE) model presents the appropriate estimators (Chang et al., 2010, 2011, 2013).

\section{Data and Descriptive Statistics}

For our empirical application, the volatility of daily prices is selected, because the MGARCH models are mostly appropriate for daily frequency. The dataset covers 2660 daily observations from March 22, 2004 to May 29, 2014, selected because volatility clustering was highly observed during this period. The variable series under study are the following.

Electricity price, NYMEX, Unit:US\$/TE, Code No:NTGCSO0.

Crude oil, NYMEX, Unit:US\$/BL, Code No:NCLCSO0.

Natural Gas, NYMEX, Unit:US\$/TE, Code No:NNGCS00.

Coal, NYMEX, Unit:US\$/TE, Code No: NOLCSO0.

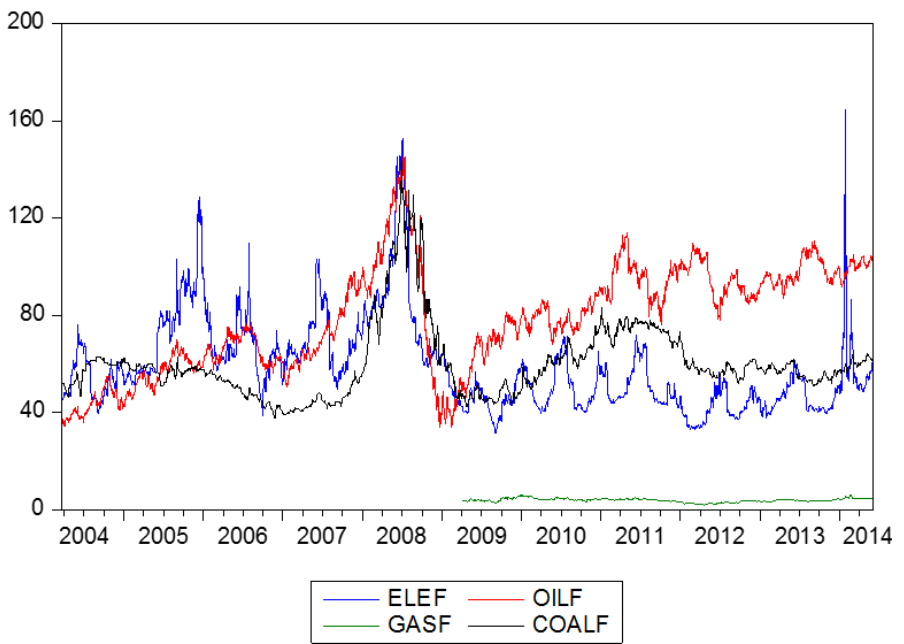

Figure 1. Plot of the energy price variables

We respectively define elef, gasf, oilf, and coalf as the natural logarithms of the future energy prices of electricity, natural gas, oil, and coal. Figure 1 plots the electricity, natural gas, oil, and coal prices. According to Figure 1, we find that electricity futures prices and oil prices are more volatile than coal futures prices. All three energy prices follow an increasing trend from 2004 to 2007, reach a peak at the beginning of 2008, and then sharply decrease at the end of 2008. The oil price is gradually increasing until 2014, while the coal price is volatile until 2014. Finally, the electricity price is volatile over the whole sample period, with a spike at the beginning of 2014. We estimate the daily price returns by taking the difference in the logarithms of two consecutive prices. Table 1 
reports the descriptive statistics for all the daily future price return series. The data suggest that average daily returns range from 0.000135 (for coal) to 0.000505 (for electricity). Unconditional volatility as measured by the standard deviation ranges from 0.011992 (for gas) to 0.039838 (for oil). The skewness value is both positive and negative. Positively skewed returns are found in coal (1.062772) and gas $(0.541167)$ energy prices, while negatively skewed returns are found in oil $(-1.287436)$ and electricity $(-0.177480)$ price returns. The kurtosis coefficients are found to be over three for all the return series. These estimates indicate that the probability distributions of the energy price returns are skewed and leptokurtic. We also apply the Ljung-Box Q statistics returns as well as square returns, which show significant serial autocorrelation in all of the return series. The statistically significant value of the ARCH-LM test indicates that the ARCH effect exists and thusthe estimation of a GARCH model is appropriate.

Table 1. Descriptive statistics for daily price

\begin{tabular}{lcccc}
\hline & OILF & ELEF & COALF & GASF \\
\hline Mean & 0.000271 & 0.000505 & 0.000135 & 0.000202 \\
Median & 0.000000 & 0.000270 & 0.000000 & 0.000000 \\
Maximum & 0.466792 & 0.089454 & 0.267712 & 0.080253 \\
Minimum & -0.456391 & -0.092572 & -0.119312 & -0.046201 \\
Std.Dev. & 0.039838 & 0.017617 & 0.031292 & 0.011992 \\
Skewness & -1.287436 & -0.17748 & 1.062772 & 0.541167 \\
Kurtosis & 49.14148 & 5.469736 & 9.427199 & 7.15335 \\
Jarque-Bera & $415.981^{* * *}$ & $510.592^{* * *}$ & $16.920^{* * *}$ & $136.836^{* * *}$ \\
L_BQ(12) & $27.101^{* * *}$ & $26.644^{* * *}$ & $130.100^{* * *}$ & $55.939^{* * * *}$ \\
L_BQ ${ }^{2}(12)$ & $287.205^{* * *}$ & $459.160^{* * *}$ & $843.490^{* * *}$ & $163.610^{* * * *}$ \\
ARCH_LM & $132.963^{* * *}$ & $179.505^{* * * *}$ & $114.869^{* * *}$ & $6.825 * * *$ \\
\hline
\end{tabular}

Note. $* * * * *$ and $*$ indicated that significant at $1 \%, 5 \%$, and $10 \%$, respectively.

A stationary process of the return series is tested using the ADF and PP unit root tests. Table 2 shows the results of these tests. Table 2 provides tests of unit roots in the level and first difference of individual energy prices. The results fail to reject the null hypothesis of unit roots in the level, but do reject the hypothesis in first difference. Therefore, we conclude that all of the energy prices are first difference (I(1)) stationary.

Table 2. ADF and PP of unit roots

\begin{tabular}{ccccc}
\hline & \multicolumn{2}{c}{ ADF } & PP \\
\cline { 2 - 5 } variables & level & lst difference & level & lst difference \\
\hline LOILF & -0.699 & $-53.551 * * *$ & -0.779 & $-53.692^{* * *}$ \\
LELEF & -0.110 & $-51.771 * * *$ & -0.050 & $-42.925 * * *$ \\
LCOALF & -0.050 & $-42.925 * * *$ & -0.046 & $-43.250^{* * *}$ \\
LGASF & -0.170 & $-25.460^{* * *}$ & -0.194 & $-41.337 * * *$ \\
\hline
\end{tabular}

Note. $* * * * *$ and $*$ indicated that significant at $1 \%, 5 \%$, and $10 \%$, respectively.

\section{Empirical Results}

This section presents the empirical results obtained from estimating multivarite GARCH models. Five multivariate GARCH models (VAR(1)-BEKK-MGARCH, VAR(1)-CCC-MGARCH, VAR(1)-DCC-MGARCH, VAR(1)-VARMA-CCC-MGRCH, and VAR(1)-VARMA-DCC-MGARCH are estimatedto analyze the mean and volatility spillover among electricity price returns and other energy price markets. We also estimate five multivariate asymmetric GARCH models (VAR(1)-BEKK-AMGARCH, VAR(1)-CCC-AMGARCH, VAR(1)-DCC-AMGARCH, VAR(1)-VARMA-CCC-AMGARCH, and VAR(1)-VARMA-DCC-AMGARCH) to set up the volatilities and conditional correlations between the electricity price, oil price, natural gas price, and coal price markets.

\subsection{Price and Volatility Spillovers-Symmetric Multivarite GARCH Models}

Table 3 and 4 presents the estimation results for five symmetric-MGARCH models. In terms of the mean equations, there are positive and negative statistically significant own mean spillover effects for electricity and 
gas (B11, B33, and B44). For electricity, gas, and coal, these price markets depend on their own past returns. This finding shows some evidence of short-term predictability for energy price changes over time. For the electricity market mean equation, there is a statistically significant negative coefficient of natural gas price across mean spillover effect to the electricity price market, telling us that an increase of lag one period in natural gas price decrease electricity prices. However, the positively statistical significant coefficient of $B 14$ indicates that the increasing price of coal also decreases the cost of electricity and then increases the price of electricity. For the coal equation, the estimated coefficient (B34) is positive and statistically significant for all models, exhibiting that the increasing price of coal will increase the price of natural gas. For the oil equation, there is no coefficients are statistically significant at own lag and cross all other price markets. Therefore, there is no evidence for persistence in returns. In general, we find that there are significant price spillover effects from gas and coal prices to electricity prices and for coal prices to gas prices, except for the CCC model. The own lag period price spillover effects are found for electricity, gas and coal prices, but not for oil prices.

Table 3. Multivariate symmetric GARCH parameter estimates(ELEF-OILF-GASF-COALF)

\begin{tabular}{|c|c|c|c|c|c|c|c|c|c|c|}
\hline \multirow[b]{2}{*}{ variable } & \multicolumn{2}{|c|}{ BEKK } & \multicolumn{2}{|c|}{$\mathrm{CCC}$} & \multicolumn{2}{|c|}{ DCC } & \multicolumn{2}{|c|}{ VARMA-CCC } & \multicolumn{2}{|c|}{ VARMA-DCC } \\
\hline & coeff. & t-stat. & coeff. & t-stat. & coeff. & t-stat. & coeff. & t-stat. & coeff. & t-stat. \\
\hline \multicolumn{11}{|l|}{ Mean } \\
\hline B10 & 0.001 & 0.997 & -0.000 & -0.252 & -0.000 & -0.328 & $0.001 * * *$ & 26.124 & $0.001 * * *$ & 7.367 \\
\hline B11 & $0.369^{* * *}$ & 10.157 & $0.282 * * *$ & 7.957 & $0.286^{* * *}$ & 7.641 & $0.298 * * *$ & 92.008 & $0.222 * * *$ & 150.594 \\
\hline B12 & -0.011 & -0.381 & -0.050 & -1.589 & -0.048 & -1.425 & $-0.029 * * *$ & 95.812 & -0.015 & -1.117 \\
\hline B13 & $-0.215^{* * *}$ & -8.185 & $-0.294 * *$ & -13.330 & $-0.289 * * *$ & -13.095 & $-0.219^{* * *}$ & -93.541 & $-0.089 * * *$ & -15.639 \\
\hline B14 & $0.126 * *$ & 2.487 & $0.089 *$ & 1.686 & 0.088 & 1.486 & $-0.060 * * *$ & -26.845 & $0.035 * *$ & 2.211 \\
\hline B20 & 0.000 & 0.771 & 0.000 & 1.154 & 0.000 & 1.118 & $0.001 * * *$ & 124.189 & 0.000 & 1.383 \\
\hline B21 & -0.007 & -0.643 & -0.000 & -0.483 & -0.000 & -0.541 & $-0.013^{* * *}$ & -52.288 & -0.002 & -0.220 \\
\hline B22 & 0.003 & 0.136 & -0.000 & -0.242 & -0.000 & -0.325 & $-0.008^{* * *}$ & -76.717 & 0.006 & 0.282 \\
\hline B23 & 0.002 & 0.160 & 0.014 & 0.923 & 0.015 & 1.024 & $0.036^{* * *}$ & 74.657 & 0.018 & 1.468 \\
\hline B24 & 0.001 & 0.018 & 0.013 & 0.378 & 0.000 & 0.166 & $0.044^{* * *}$ & 50.514 & 0.004 & 0.140 \\
\hline B30 & 0.000 & 0.238 & -0.000 & -0.296 & -0.000 & -0.324 & $-0.000^{* * *}$ & -910.471 & $0.000 *$ & 1.905 \\
\hline B31 & -0.010 & -0.491 & 0.012 & 0.573 & 0.000 & 0.089 & $0.022 * * *$ & 23.893 & $-0.029 * * *$ & -3.492 \\
\hline B32 & 0.033 & 0.924 & -0.000 & -0.169 & 0.000 & -0.045 & $-0.000^{* * *}$ & -26.426 & $-0.059^{*}$ & -3.173 \\
\hline B33 & $-0.086 * * *$ & -3.406 & $-0.160 * * *$ & -5.313 & $-0.137 * * *$ & -4.430 & $-0.139 * * *$ & -36.593 & $-0.077 * * *$ & -5.012 \\
\hline B34 & $0.197 * * *$ & 3.474 & $0.209^{* * *}$ & 3.534 & $0.200 * * *$ & 3.293 & $0.146^{* * *}$ & 52.564 & $0.195 * * *$ & 4.940 \\
\hline B40 & 0.000 & 0.725 & 0.000 & 0.520 & 0.000 & 0.346 & $0.000^{* * * *}$ & 553.216 & 0.000 & 1.465 \\
\hline B41 & 0.010 & 1.177 & -0.000 & 0.589 & 0.000 & 0.624 & $-0.005^{* * *} *$ & -10.983 & 0.000 & 0.296 \\
\hline B42 & -0.024 & 0.016 & $-0.029 *$ & -1.699 & $-0.029^{*}$ & -1.773 & $-0.028 * * *$ & -17.089 & -0.022 & -1.829 \\
\hline B43 & -0.010 & 0.009 & -0.014 & -1.4197 & -0.014 & -1.352 & $-0.007 * * *$ & -28.276 & -0.011 & -1.049 \\
\hline B44 & $0.243 * * *$ & 10.187 & $0.271 * * *$ & 0.031 & $0.268 * * *$ & 8.208 & $0.279 * * *$ & 22.608 & $0.273 * * *$ & 10.892 \\
\hline \multicolumn{11}{|l|}{ Variance } \\
\hline $\mathrm{C}(1,1)$ & $0.013 * * *$ & 16.303 & $0.000 * * *$ & 8.231 & 0.000 & 0.346 & $0.000 * * *$ & 145.043 & $-0.000 * * *$ & -19.800 \\
\hline $\mathrm{C}(2,1)$ & -0.000 & -0.168 & & & & & & & & \\
\hline $\mathrm{C}(2,2)$ & $0.001 * * *$ & 3.913 & $0.000 * *$ & 2.196 & $0.000^{* * * *}$ & 7.875 & $0.000^{* * *} *$ & 35.210 & $0.000 * * *$ & 78.006 \\
\hline $\mathrm{C}(3,1)$ & $0.003 * * *$ & 3.561 & & & & & & & & \\
\hline $\mathrm{C}(3,2)$ & 0.002 & 1.679 & & & & & & & & \\
\hline $\mathrm{C}(3,3)$ & 0.000 & 0.001 & $0.000^{* * *}$ & 3.666 & $0.000^{* * *}$ & 3.696 & $-0.000 * * *$ & -106.38 & $0.001^{* * *}$ & 53.568 \\
\hline $\mathrm{C}(4,1)$ & -0.000 & -0.007 & & & & & & & & \\
\hline $\mathrm{C}(4,2)$ & $-0.002 * * *$ & -3.629 & & & & & & & & \\
\hline $\mathrm{C}(4,3)$ & -0.000 & -0.002 & & & & & & & & \\
\hline $\mathrm{C}(4,4)$ & 0.000 & 0.000 & $0.000 * *$ & 2.256 & $0.000 * *$ & 2.354 & $0.000 * * *$ & 32.091 & $0.000 * * *$ & 13.108 \\
\hline $\mathrm{A}(1,1)$ & $1.071 * * *$ & 27.773 & $0.807 * * *$ & 8.985 & $0.776^{* * *}$ & 9.222 & $0.488^{* * *} *$ & 56.328 & $0.581^{* * *} *$ & 137.125 \\
\hline $\mathrm{A}(1,2)$ & -0.001 & -0.650 & & & & & $-0.279 * * *$ & -33.952 & $-0.159 * *$ & -6.979 \\
\hline $\mathrm{A}(1,3)$ & $0.089 * * *$ & 3.514 & & & & & $0.169 * * *$ & 88.922 & $-0.177 * * *$ & -15.812 \\
\hline $\mathrm{A}(1,4)$ & $0.003 * * *$ & 0.323 & & & & & $-0.467 * * *$ & -344.988 & $-0.125 * * *$ & -4.439 \\
\hline $\mathrm{A}(2,1)$ & $-0.116^{* * *}$ & -2.875 & & & & & $0.015^{* * *}$ & 15.321 & $0.008 * * *$ & 3.498 \\
\hline $\mathrm{A}(2,2)$ & $0.097 * * *$ & 4.283 & $0.043 * * *$ & 4.426 & $0.045^{* * *}$ & 3.759 & $0.131 * * *$ & 60.272 & $0.031 * * *$ & 29.595 \\
\hline $\mathrm{A}(2,3)$ & $0.073^{* *}$ & 1.925 & & & & & $0.372 * * *$ & 252.507 & $0.017 * * *$ & 2.846 \\
\hline $\mathrm{A}(2,4)$ & 0.018 & 1.336 & & & & & $-0.037 * * *$ & -76.246 & $0.034 * * *$ & 5.076 \\
\hline
\end{tabular}


Table 4. Multivariate symmetric GARCH parameter estimates (Continued)

\begin{tabular}{|c|c|c|c|c|c|c|c|c|c|c|}
\hline \multirow[b]{2}{*}{ variable } & \multicolumn{2}{|c|}{ BEKK } & \multicolumn{2}{|c|}{$\mathrm{CCC}$} & \multicolumn{2}{|c|}{ DCC } & \multicolumn{2}{|c|}{ VARMA-CCC } & \multicolumn{2}{|c|}{ VARMA-DCC } \\
\hline & coeff. & t-stat. & coeff. & t-stat. & coeff. & t-stat. & coeff. & t-stat. & coeff. & t-stat. \\
\hline $\mathrm{A}(3,1)$ & $-0.599 * * *$ & -15.699 & & & & & $0.063 * * *$ & 306.670 & $0.005 * * *$ & 7.346 \\
\hline $\mathrm{A}(3,2)$ & $-0.019^{*}$ & -1.683 & & & & & $-0.072 * * *$ & -97.945 & $-0.078 * * *$ & -9.182 \\
\hline $\mathrm{A}(3,3)$ & $0.126^{* * *}$ & 4.355 & $0.065^{* * *}$ & 6.309 & $0.068 * * *$ & 6.421 & $0.030 * * *$ & 131.174 & $0.258 * * *$ & 62.966 \\
\hline $\mathrm{A}(3,4)$ & $0.028 * * *$ & 3.051 & & & & & $-0.078 * * *$ & -82.657 & $-0.327 * * *$ & -32.346 \\
\hline $\mathrm{A}(4,1)$ & $0.521 * * *$ & 7.844 & & & & & $-0.025^{* * * *}$ & -18.850 & $-0.026^{* * *}$ & -34.355 \\
\hline $\mathrm{A}(4,2)$ & $0.050^{*}$ & 1.966 & & & & & $-0.022 * * *$ & -38.155 & $-0.058 * * *$ & -6.908 \\
\hline $\mathrm{A}(4,3)$ & 0.023 & 0.420 & & & & & $0.043^{* * *}$ & 49.866 & $0.019^{*}$ & 2.11808 \\
\hline $\mathrm{A}(4,4)$ & $0.128^{* * *}$ & 4.447 & $0.126^{* * *}$ & 4.603 & $0.138^{* * *}$ & 4.826 & $0.117 * * *$ & 109.211 & $0.158 * * *$ & 13.673 \\
\hline $\mathrm{B}(1,1)$ & $0.535^{* * *}$ & 26.133 & $0.360 * * *$ & 8.805 & $0.374 * * *$ & 9.683 & $0.462 * * *$ & 135.732 & $-0.212 * * *$ & -187.348 \\
\hline $\mathrm{B}(1,2)$ & 0.003 & 0.539 & & & & & $4.268^{* * *}$ & 98.492 & $-0.208^{*}$ & -1.676 \\
\hline $\mathrm{B}(1,3)$ & $-0.039^{*}$ & -2.488 & & & & & $0.818^{* * *}$ & 60.271 & $3.465 * * *$ & 377.545 \\
\hline $\mathrm{B}(1,4)$ & -0.001 & -0.185 & & & & & $-5.898 * * *$ & -38.454 & $-6.457 * * *$ & 104.023 \\
\hline $\mathrm{B}(2,1)$ & -0.035 & -1.060 & & & & & $1.852 * * *$ & 43.854 & $-0.083^{* * *}$ & -4.8800 \\
\hline $\mathrm{B}(2,2)$ & $0.989 * * *$ & 344.974 & $0.947 * * *$ & 79.792 & $0.945^{* * *}$ & 63.489 & $0.644 * * *$ & 116.492 & $0.928 * * *$ & 477.916 \\
\hline $\mathrm{B}(2,3)$ & $-0.052 * * *$ & -5.249 & & & & & $0.718^{* * *}$ & 75.411 & $0.013 * * *$ & 9.936 \\
\hline $\mathrm{B}(2,4)$ & $0.009 *$ & 2.284 & & & & & $0.444 * * *$ & 199.367 & $0.135^{* * *}$ & 20.534 \\
\hline $\mathrm{B}(3,1)$ & $0.156^{* * *}$ & 8.139 & & & & & $-0.081 * * *$ & -295.639 & $0.616^{* * *}$ & 117.705 \\
\hline $\mathrm{B}(3,2)$ & $0.008 * *$ & 2.317 & & & & & $2.123^{* * *}$ & 773.463 & $1.773 * * *$ & 54.106 \\
\hline $\mathrm{B}(3,3)$ & $0.982 * * *$ & 111.980 & $0.913 * * *$ & 71.351 & $0.910 * * *$ & 69.415 & $0.824 * * *$ & 797.299 & $-0.113 * * *$ & -34.812 \\
\hline $\mathrm{B}(3,4)$ & $-0.020 * * *$ & -6.005 & & & & & $1.080^{* * *}$ & 657.123 & $3.869 * * *$ & 75.107 \\
\hline $\mathrm{B}(4,1)$ & 0.093 & 1.515 & & & & & $-0.194 * * *$ & -326.372 & $-0.103 * * *$ & -5.144 \\
\hline $\mathrm{B}(4,2)$ & 0.002 & 0.177 & & & & & $-0.485^{* * *}$ & -45.066 & $0.482 * * *$ & 22.468 \\
\hline $\mathrm{B}(4,3)$ & $0.145^{* * *}$ & 6.309 & & & & & $0.904 * * *$ & 55.341 & $0.336^{* * *}$ & 23.918 \\
\hline $\mathrm{B}(4,4)$ & $0.980 * * *$ & 85.318 & $0.733 * * *$ & 8.944 & $0.709 * * *$ & 8.326 & $0.197 * * *$ & 18.174 & $0.294 * * *$ & 19.967 \\
\hline $\mathrm{R}(2,1)$ & & & 0.020 & 0.777 & & & $-0.008 * * *$ & -64.189 & & \\
\hline $\mathrm{R}(3,1)$ & & & $0.468 * * *$ & 23.452 & & & $0.470 * * *$ & 54.507 & & \\
\hline $\mathrm{R}(3,2)$ & & & $0.133 * * *$ & 5.175 & & & $0.109 * * *$ & 626.596 & & \\
\hline $\mathrm{R}(4,1)$ & & & $0.134 * * *$ & 5.221 & & & $0.127 * * *$ & 104.461 & & \\
\hline $\mathrm{R}(4,2)$ & & & $0.259 * * *$ & 11.059 & & & $0.245^{* * *}$ & 943.169 & & \\
\hline $\mathrm{R}(4,3)$ & & & $0.215^{* * *}$ & 8.488 & & & $0.209 * * *$ & 426.658 & & \\
\hline $\operatorname{DCC}(1)$ & & & & & $0.029 *$ & 2.545 & & & $0.012 * * *$ & 53.265 \\
\hline $\operatorname{DCC}(2)$ & & & & & $0.642 * * *$ & 4.618 & & & $0.841 * * *$ & 36.834 \\
\hline $\log L$ & 13707.376 & & 13645.867 & & 13647.200 & & 13689.225 & & 13695.462 & \\
\hline AIC & -10.221 & & -10.460 & & -10.588 & & -10.734 & & -10.978 & \\
\hline SBC & -10.107 & & -10.235 & & -10.370 & & -10.555 & & -10.811 & \\
\hline
\end{tabular}

Note. ${ }^{* * *}, * *$ and $*$ indicated that significant at $1 \%, 5 \%$, and $10 \%$, respectively.

For the variance equation, the elements of the A matrix are estimated coefficients for the ARCH volatility that measure short-term volatility persistence. The own conditional ARCH effects $A_{11}, A_{22}, A_{33}$ and $A_{44}$ are statistically positive significant at the $1 \%$ level, presenting considerable evidence of short-term persistence. In addition, the conditional variances are a function of the own lagged covariance and lagged cross-product of the shocks. From the variance equation, the BEKK and VARMA-GARCH models also measure short-term volatility spillover between energy prices. The positive and significant coefficients of $A_{13}$ state that a shock of gas volatility spills over to the electricity price market. The negative statistically significant coefficient of $A_{32}$ displays cross and feed-back effects between oil and gas markets.

For the variance equation, own conditional GARCH effect $\left(B_{i j}\right)$, the elements of $B$ matrix are the estimated coefficients for the GARCH volatility thatmeasure long-term persistence. According to the variance equation of Table 4, the positive and statistically significant coefficients of $B_{i j}$ note own long-term volatility persistence. From the variance equation, we observe that, in addition to own past innovations, the conditional variance in each market is also affected by innovations coming at least from one of the other markets. There are positive significant volatility spillovers from the coal price market to the oil price market, the oil price market to the gas price market, and the gas price market to the coal price market. However, for the VARMA-CCC and DCC 
models, the positive significant volatility spillover effectsare from gas to electricity, while there are negative effects from coal to electricity. Those energy price volatility spillovers affecting each other directly or indirectly may be due to common fundamental factors that influence energy equity markets.

For the DCC model, the estimations of the DCC parameter (DCC(1) and DCC(2)) are positively statistically significant at the $1 \%$ level for the DCC and VARMA models. These estimated coefficients sum to a value that is less than one, indicating that the dynamic conditional correlations are mean reverting and the significantly coefficients leading to a rejection of the assumption of CCC for all news to return. The short-run persistence of shocks on DCC is the highest for electricity at 0.776, while the largest long-run persistence of shocks to DCC is 0.945 for oil. The magnitude of the DCC estimator of the VARMA model is greater than that for the DCC model. As in the case of Table 4, the estimated value of short-run own volatility persistence is larger than the cross volatility effect for the electricity market, and the estimated value of the long-run own volatility persistence is also larger than the cross volatility effect for each market under the BEKK model.

For the residual diagnostic test of Table 5, the estimated coefficients of the AIC and SBC criteria display that the VARMA-DCC model is the best model for each of the energy markets. The residual diagnostic test of the standardized residuals (Q-statistics) exhibits no statistically significant evidence of autocorrelation in the standardized results (ARCH effect) at the $1 \%$ level. Moreover, the Q-square statistics show no statistically significant evidence of the GARCH effect at the $1 \%$ level. Based on the residual diagnostic test, we find that the VARMA-DCC model is chosen as the best of the models versus the other MGARCH models.

Table 5. Residual diagnostic test

\begin{tabular}{|c|c|c|c|c|c|c|c|c|c|c|c|c|c|c|c|c|c|c|c|c|}
\hline & \multicolumn{4}{|c|}{ BEKK } & \multicolumn{4}{|c|}{$\mathrm{CCC}$} & \multicolumn{4}{|c|}{ DCC } & \multicolumn{4}{|c|}{ VARMA-CCC } & \multicolumn{4}{|c|}{ VARMA-DCC } \\
\hline & Elef & Oilf & Gasf & Coalf & Elef & Oilf & Gasf & Coalf & Elef & Oilf & Gasf & Coalf & Elef & Oilf & Gasf & Coalf & Elef & Oilf & Gas & Coalf \\
\hline ARCH-LM & 1.168 & 0.657 & 0.731 & 0.505 & 1.011 & 0.704 & 0.711 & 0.547 & 1.002 & 0.599 & 0.762 & 0.613 & 1.332 & 0.697 & 0.701 & 0.585 & 1.057 & 0.607 & 0.709 & 0.609 \\
\hline$Q$-stat & 20.34 & 18.66 & 11.79 & 15.61 & 20.71 & 18.19 & 12.01 & 15.69 & 21.12 & 19.00 & 11.11 & 15.79 & 20.88 & 16.99 & 10.89 & 15.14 & 22.8 & 18.71 & 11.91 & 15.77 \\
\hline$Q^{2}$-stat & 7.69 & 5.71 & 4.88 & 7.25 & 7.99 & 5.32 & 5.09 & 6.98 & 6.99 & 5.11 & 3.97 & 7.33 & 7.13 & 5.43 & 5.16 & 6.90 & 7.81 & 5.32 & 4.79 & 7.14 \\
\hline
\end{tabular}

\subsection{Price and Volatility Spillover-Asymmetric Multivariate GARCH Models}

We now can discuss the results estimated by the four-variable asymmetric MGARCH models as presented in Table 6 and 7. Regression results are presented for five models: VAR(1)-BEKK-AGARCH, VAR(1)-CCC-AGARCH, VAR(1)-DCC-AGARCH, VAR(1)-CCC-VARMA-AGARCH, and VAR(1)-DCCVARMA-AGARCH. We first look at the mean equation, with electricity, natural gas, and coal price current returns depending on their own past returns $\left(B_{11}, B_{33}\right.$ and $\left.B_{44}\right)$. Here, the one-period lagged values of the energy price returns are largely determined by their current values at different levels. This suggests that the past returns can be used to forecast future returns in these markets, indicating short-term predictability in energy price changes. For the electricity, natural gas, and coal price markets, the lag one period return influences the current return. For the electricity equation, the estimated coefficients of $B_{12}$ and $B_{13}$ are each negative and statistically significant in each of the three models that are not VARMA. It indicates the return transmission from oil and gas to the electricity market. For the gas equation, the estimated coefficients of $B_{34}$ are positive and statistically significant in each specification. In terms of the information transmission through returns, the natural gas price returns are affected by the coal price returns. For the oil and coal equations, there is no considerable evidence of the estimated coefficients being statistically significant across all models. The analysis shows that the electricity, gas, and coal returns are more related to their own past returns, however, there is not much evidence of price transmission effects in mean equations, except for oil and gas to electricity and for gas to coal. 
Table 6. Multivariate asymmetric GARCH parameter estimates (ELEF-OILF-GASF-COALF)

\begin{tabular}{|c|c|c|c|c|c|c|c|c|c|c|}
\hline \multirow[b]{2}{*}{ variable } & \multicolumn{2}{|c|}{ BEKK } & \multicolumn{2}{|c|}{$\mathrm{CCC}$} & \multicolumn{2}{|c|}{ DCC } & \multicolumn{2}{|c|}{ VARMA-CCC } & \multicolumn{2}{|c|}{ VARMA-DCC } \\
\hline & coeff. & t-stat. & coeff. & t-stat. & coeff. & t-stat. & coeff. & t-stat. & coeff. & t-stat. \\
\hline \multicolumn{11}{|l|}{ Mean } \\
\hline B10 & 0.0005 & 0.8381 & -0.0005 & -1.1255 & $-0.0034 * * *$ & -7.5841 & $0.0010^{* * * *}$ & 10.4853 & $0.0011^{* * *}$ & 163.5935 \\
\hline B11 & $0.3714 * * *$ & 10.3146 & $0.2721 * * *$ & 6.7986 & $0.3890 * * *$ & 15.5073 & $0.1692 * * *$ & 28.3297 & $0.1547 * * *$ & 864.7315 \\
\hline B12 & -0.1167 & -0.3868 & $-0.0457 * * *$ & -3.8492 & $-0.1003 * * *$ & -4.5681 & $-0.0679 * * *$ & -29.7524 & $-0.0964 * * *$ & -87.2012 \\
\hline B13 & $-0.1998 * * *$ & -7.2591 & $-0.2957 * * *$ & -21.1135 & $-0.2435^{* * *}$ & -21.5290 & $0.0122 * * *$ & 6.7214 & $0.0093 * * *$ & 115.1704 \\
\hline B14 & $0.1345^{* * *}$ & 2.6893 & $0.08918 * *$ & 2.0581 & -0.0029 & -0.1369 & $-0.0152 * * *$ & -5.2089 & $-0.0822 * * *$ & -508.1074 \\
\hline B20 & 0.0000 & 0.1139 & 0.0002 & 0.6435 & 0.0001 & 0.1981 & 0.0004 & 1.6147 & $0.0001 * * *$ & 38.2693 \\
\hline B21 & -0.0126 & -1.1883 & -0.0043 & -0.4298 & -0.0067 & -0.7144 & 0.0007 & 0.1309 & $-0.01311^{* * * *}$ & -143.5341 \\
\hline B22 & -0.0033 & -0.1306 & -0.0042 & -0.1653 & $0.0494 *$ & 1.8463 & -0.003 & -1.0774 & $0.0000^{* * * *}$ & 42.0473 \\
\hline B23 & 0.0071 & 0.5335 & 0.0108 & 0.7958 & 0.0154 & 1.1709 & $0.0063^{* * *}$ & 2.3864 & $0.01378 * * *$ & 97.4384 \\
\hline B24 & 0.0063 & 0.1908 & 0.0259 & 0.7917 & -0.0433 & -1.2780 & $0.0184 * * *$ & 3.0501 & $0.0156^{* * *}$ & 49.9715 \\
\hline B30 & 0.0001 & 0.1249 & -0.0009 & -1.4904 & $-0.0027 * * *$ & -3.9844 & $-0.0003 * * *$ & -3.4881 & $-0.0004 * * *$ & -94.9822 \\
\hline B31 & 0.0123 & 0.5832 & 0.0094 & 0.5325 & 0.0054 & 0.3309 & $-0.0219 * * *$ & -2.7594 & $-0.0255^{* * *}$ & -856.2304 \\
\hline B32 & 0.0312 & 0.9192 & -0.0032 & -0.0961 & -0.0300 & -0.8158 & 0.0002 & 0.0068 & $0.0061^{* * *}$ & 34.0973 \\
\hline B33 & $-0.0803 * * *$ & -3.1604 & $-0.1514 * * *$ & -6.3006 & $-0.0829 * * *$ & -3.2073 & $-0.0289 * * *$ & -3.6516 & $-0.0274 * * *$ & -89.6655 \\
\hline B34 & $0.2051 * * *$ & 3.8090 & $0.1925 * * *$ & 3.3982 & $0.1689 * * *$ & 3.0141 & $0.1655^{* * *} *$ & 4.7775 & $0.1445^{* * *}$ & 77.3832 \\
\hline B40 & 0.0000 & 0.2118 & -0.0000 & -0.3977 & $-0.0007 * * *$ & -3.2957 & $0.0001 *$ & 1.7829 & $-0.0000 * * *$ & -61.6670 \\
\hline B41 & 0.0067 & 0.8122 & 0.0049 & 0.7300 & -0.0045 & -0.6531 & 0.0002 & 0.1861 & $-0.0036^{* * * *}$ & -574.3116 \\
\hline B42 & -0.0274 & -1.6353 & $-0.0374 * * *$ & -4.0693 & -0.0201 & -1.3498 & $-0.0265 * * *$ & -18.0473 & $-0.0229 * * *$ & -318.0272 \\
\hline B43 & -0.0038 & -0.3903 & $-0.0186^{* *}$ & -2.5445 & 0.0089 & 0.9420 & $-0.0145 * * *$ & -11.9170 & $-0.0143^{* * *} *$ & -508.2969 \\
\hline B44 & $0.2246^{* * *}$ & 8.9705 & $0.2872 * * *$ & 12.5279 & $0.2277 * * *$ & 9.2108 & $0.2834 * * *$ & 94.9589 & $0.2683 * * *$ & 687.2374 \\
\hline \multicolumn{11}{|l|}{ Variance } \\
\hline $\mathrm{C}(1,1)$ & $0.0128^{* * *}$ & 13.0731 & $-1.7730 * * *$ & -11.6768 & $-2.6018 * * *$ & -156.1905 & $0.0000 * * *$ & 18.4718 & $0.0002 * * *$ & 341.8299 \\
\hline $\mathrm{C}(2,1)$ & 0.000 & 0.0365 & & & & & & & & \\
\hline $\mathrm{C}(2,2)$ & $-0.0000 * * *$ & -2.6416 & $-0.3191 * * *$ & -4.4466 & $-0.2309 * * *$ & -19.0519 & $-0.0000 * * *$ & -39.9018 & $-0.0000 * * *$ & -102.8287 \\
\hline $\mathrm{C}(3,1)$ & $0.0024^{* * *} *$ & 2.8907 & & & & & & & & \\
\hline $\mathrm{C}(3,2)$ & -0.0019 & -3.0719 & & & & & & & & \\
\hline$C(3,3)$ & 0.0000 & 0.0003 & $-0.3363 * * *$ & -5.2382 & $-2.3616^{* * *}$ & -126.738 & -0.0000 & -15.1247 & $-0.0001 * * *$ & -587.2904 \\
\hline $\mathrm{C}(4,1)$ & -0.0004 & -0.7126 & & & & & & & & \\
\hline $\mathrm{C}(4,2)$ & 0.0014 & 3.6142 & & & & & & & & \\
\hline $\mathrm{C}(4,3)$ & 0.0000 & -0.0008 & & & & & & & & \\
\hline $\mathrm{C}(4,4)$ & 0.0000 & -0.0001 & $-1.1874 * * *$ & -3.8423 & $-4.7149 * * *$ & -223.5130 & $0.0000^{* * *}$ & 391.4862 & $0.0003^{* * *}$ & 553.584 \\
\hline $\mathrm{A}(1,1)$ & $0.9906^{* * *}$ & 16.6481 & $0.7029^{* * *}$ & 13.7594 & $0.8677 * * *$ & 16.5046 & $0.4696^{* * *}$ & 541.5870 & $0.5539 * * *$ & 547.307 \\
\hline $\mathrm{A}(1,2)$ & -0.0117 & -1.1492 & & & & & $-0.3232 * * *$ & -628.2661 & $-0.2731 * * *$ & -178.7385 \\
\hline $\mathrm{A}(1,3)$ & $0.1105^{* * * *}$ & 4.4816 & & & & & $0.1080 * * *$ & 311.9547 & $0.006^{* * *}$ & 109.147 \\
\hline $\mathrm{A}(1,4)$ & 0.0005 & 0.0597 & & & & & $-0.5029 * * *$ & -660.2993 & $-0.4325^{* * *} *$ & -643.6746 \\
\hline $\mathrm{A}(2,1)$ & $-0.1395 * * *$ & -3.8899 & & & & & $0.0049 * * *$ & 2.5559 & $-0.0052 * * *$ & -183.4503 \\
\hline $\mathrm{A}(2,2)$ & $0.0704 * * *$ & 3.0718 & $0.0563^{* * *}$ & 2.6919 & $0.0381 * * *$ & 2.3064 & $0.0131 * * *$ & 39.5071 & $0.0310 * * *$ & 129.9564 \\
\hline $\mathrm{A}(2,3)$ & 0.0473 & 1.4012 & & & & & $0.0195^{* * *}$ & 5.2335 & $0.0163 * * *$ & 184.7724 \\
\hline $\mathrm{A}(2,4)$ & 0.0306 & 2.3933 & & & & & $0.0172 * * *$ & 13.2711 & $-0.0750 * * *$ & -90.7212 \\
\hline
\end{tabular}

Table 7. Multivariate asymmetric GARCH parameter estimates (Continued)

\begin{tabular}{|c|c|c|c|c|c|c|c|c|c|c|}
\hline \multirow[b]{2}{*}{ variable } & \multicolumn{2}{|c|}{ BEKK } & \multicolumn{2}{|l|}{$\mathrm{CCC}$} & \multicolumn{2}{|c|}{ DCC } & \multicolumn{2}{|c|}{ VARMA-CCC } & \multicolumn{2}{|c|}{ VARMA-DCC } \\
\hline & coeff. & t-stat. & coeff. & t-stat. & coeff. & t-stat. & coeff. & t-stat. & coeff. & t-stat. \\
\hline $\mathrm{A}(3,1)$ & $-0.5837 * * *$ & -14.4702 & & & & & $0.0774 * * *$ & 103.0077 & $0.0696^{* * *}$ & 896.5051 \\
\hline $\mathrm{A}(3,2)$ & -0.0026 & -0.2077 & & & & & $-0.0889 * * *$ & -241.6020 & $-0.0644 * * *$ & -972.5368 \\
\hline $\mathrm{A}(3,3)$ & $0.0982 * * *$ & 3.9872 & $0.1076^{* * * *}$ & 4.9433 & $0.1114 * * *$ & 3.2359 & $0.0060 * * *$ & 43.8808 & $0.0132 * * *$ & 354.4112 \\
\hline $\mathrm{A}(3,4)$ & $0.0178 * *$ & 1.7684 & & & & & $-0.0596^{* * *}$ & -113.5523 & $-0.1382 * * *$ & -243.2561 \\
\hline $\mathrm{A}(4,1)$ & $0.5011 * * *$ & 7.0990 & & & & & $-0.0207 * * *$ & -46.1477 & $-0.0215 * * *$ & -872.3318 \\
\hline $\mathrm{A}(4,2)$ & 0.0348 & 1.2589 & & & & & $-0.0181 * * *$ & -17.7386 & $0.0074 * * *$ & 166.5552 \\
\hline $\mathrm{A}(4,3)$ & -0.0050 & -0.1003 & & & & & $-0.0183^{* * *} *$ & -27.4592 & $0.0129 * * *$ & 339.6110 \\
\hline $\mathrm{A}(4,4)$ & $0.1571 * * *$ & 6.6407 & $0.3427 * * *$ & 7.0914 & & & $0.1671 * * *$ & 173.9846 & $0.1354 * * *$ & 108.3268 \\
\hline
\end{tabular}




\begin{tabular}{|c|c|c|c|c|c|c|c|c|c|c|}
\hline $\mathrm{B}(1,1)$ & $0.5371 * * *$ & 14.2868 & $0.8075^{* * * *}$ & 40.6289 & $0.7060 * * *$ & 234.5857 & 0.3466 *** & 622.7646 & $0.3489 * * *$ & 542.3000 \\
\hline $\mathrm{B}(1,2)$ & 0.0047 & 0.9204 & & & & & $-7.1517 * * *$ & -169.6084 & $-2.1213 * * *$ & -170.0603 \\
\hline $\mathrm{B}(1,3)$ & $-0.0494 * * *$ & -3.3752 & & & & & $0.2278 * * *$ & 165.3743 & $0.5102^{* * *}$ & 827.3705 \\
\hline $\mathrm{B}(1,4)$ & 0.0004 & 0.0729 & & & & & $6.6825 * * *$ & 211.2386 & $-1.5161 * * *$ & -306.7516 \\
\hline $\mathrm{B}(2,1)$ & -0.0252 & -0.7606 & & & & & $-0.1368 * * *$ & -15.0551 & $0.2262 * * *$ & 576.7915 \\
\hline $\mathrm{B}(2,2)$ & $0.9768 * * *$ & 239.4175 & $0.9688^{* * * *}$ & 120.3086 & $0.9771 * * *$ & 545.0635 & $0.8313 * * *$ & 736.5626 & $0.7711 * * *$ & 257.9075 \\
\hline $\mathrm{B}(2,3)$ & $-0.0399 * * *$ & -4.2078 & & & & & $-0.0621 * * *$ & -68.2129 & $-0.1143 * * *$ & -857.4574 \\
\hline $\mathrm{B}(2,4)$ & 0.0036 & 0.9754 & & & & & $0.8374 * * *$ & 232.5602 & $1.0322 * * *$ & 145.5392 \\
\hline $\mathrm{B}(3,1)$ & $0.1632 * * *$ & 7.2657 & & & & & $-0.1309 * * *$ & -458.0361 & $-0.1188 * * *$ & -166.6380 \\
\hline $\mathrm{B}(3,2)$ & 0.0025 & 0.6859 & & & & & $0.9055^{* * * *}$ & 753.8301 & $0.6952 * * *$ & 443.1556 \\
\hline $\mathrm{B}(3,3)$ & $0.9836^{* * *}$ & 125.6959 & $0.9666^{* * * *}$ & 111.5630 & $0.6909 * * *$ & 271.9692 & $0.9399 * * *$ & 180.9301 & $0.8717 * * *$ & 774.7384 \\
\hline $\mathrm{B}(3,4)$ & $-0.0186 * * *$ & -5.2618 & & & & & $0.1939 * * *$ & 145.0952 & $1.0722 * * *$ & 691.6434 \\
\hline $\mathrm{B}(4,1)$ & $0.1294 * * *$ & 1.9555 & & & & & $-0.1292 * * *$ & -102.4268 & $-0.2034 * * *$ & -152.6042 \\
\hline $\mathrm{B}(4,2)$ & -0.0046 & -0.6487 & & & & & $-0.0331 * * *$ & -26.2901 & $-0.1213 * * *$ & -899.6343 \\
\hline $\mathrm{B}(4,3)$ & $0.1325 * * *$ & 6.5452 & & & & & $0.7168 * * *$ & 265.5727 & $0.5960 * * *$ & 122.8240 \\
\hline $\mathrm{B}(4,4)$ & $0.9722 * * *$ & 105.0047 & $0.8916^{* * * *}$ & 27.2016 & $0.5006^{* * * *}$ & 215.4998 & 0.4169 *** & 376.9435 & $0.3563 * * *$ & 116.4740 \\
\hline $\mathrm{D}(1,1)$ & 0.6175 & 4.6450 & $-6.8075 * * *$ & -2.5188 & -1.0901 & -0.3611 & $0.0278 * * *$ & 90.5814 & $0.0703 * * *$ & 330.0173 \\
\hline $\mathrm{D}(1,2)$ & -0.0045 & -0.5436 & & & & & & & & \\
\hline $\mathrm{D}(1,3)$ & 0.0062 & 0.2473 & & & & & & & & \\
\hline $\mathrm{D}(1,4)$ & -0.0076 & -1.0467 & & & & & & & & \\
\hline $\mathrm{D}(2,1)$ & -0.6176 & -0.7963 & & & & & & & & \\
\hline $\mathrm{D}(2,2)$ & $-0.2164 * * *$ & -7.5273 & $123.6544 * * *$ & 4.0499 & $104.007 * * *$ & 22.7549 & $0.1029 * * *$ & 110.0251 & $0.1484 * * *$ & 49.7687 \\
\hline $\mathrm{D}(2,3)$ & $-0.1331 * * *$ & -2.7783 & & & & & & & & \\
\hline $\mathrm{D}(2,4)$ & -0.0281 & -1.4822 & & & & & & & & \\
\hline $\mathrm{D}(3,1)$ & $-0.2988 * * *$ & -3.9069 & & & & & & & & \\
\hline $\mathrm{D}(3,2)$ & $0.0374 * * *$ & 2.1826 & & & & & & & & \\
\hline $\mathrm{D}(3,3)$ & $0.1871 * * *$ & 4.1798 & $41.9337 * * *$ & 2.4779 & $280.3582 * * *$ & 8.6447 & $0.0264 * * *$ & 61.4916 & $0.0339 * * *$ & 881.0117 \\
\hline $\mathrm{D}(3,4)$ & $0.0788 * * *$ & 4.7784 & & & & & & & & \\
\hline $\mathrm{D}(4,1)$ & 0.1678 & 1.1625 & & & & & & & & \\
\hline $\mathrm{D}(4,2)$ & $-0.1886^{* * * *}$ & -5.9063 & & & & & & & & \\
\hline $\mathrm{D}(4,3)$ & -0.0494 & -0.6974 & & & & & & & & \\
\hline $\mathrm{D}(4,4)$ & $-0.1538 * * *$ & -3.7335 & $-601.8449 * * *$ & -3.5287 & -169.4496 & -0.8286 & $-0.0669 * * *$ & -88.9717 & $0.0226^{* * *}$ & 796.8398 \\
\hline $\mathrm{R}(2,1)$ & & & 0.0212 & 0.9129 & & & $0.0224 * * *$ & 157.8751 & & \\
\hline $\mathrm{R}(3,1)$ & & & $0.4705 * * *$ & 23.6116 & & & $0.0491 * * *$ & 767.3811 & & \\
\hline
\end{tabular}

Note. $* * * * *$ and $*$ indicated that significant at $1 \%, 5 \%$, and $10 \%$, respectively.

Turning to the conditional variance equations, the current conditional volatility of the energy markets is determined by their both own conditional ARCH effects $\left(A_{i j}\right)$ that estimate the short-run persistence and own conditional GARCH effects $\left(B_{i j}\right)$, which measure long-term persistence. The cross-market shock effects $\left(\alpha_{i j}\right)$ and volatility effects $\left(B_{i j}\right)$ also can be found from the conditional variance equation. According to Table 8 , the estimated result of the ARCH and GARCH coefficients for own conditional shock and volatility show positive and statistical significance at the $1 \%$ level $(0.9906,0.0704,0.0982$, and 0.1571 for the short-term persistence effect and $0.5371,0.9768,0.9836$, and 0.9722 for the long-term persistence effect). A larger coefficient of the GARCH effect versus the ARCH effect implies that the former effect exhibits significant volatility impacts of conditional volatility on the energy markets.

Table 8. Residual diagnostic test

\begin{tabular}{|c|c|c|c|c|c|c|c|c|c|c|c|c|c|c|c|c|c|c|c|c|}
\hline & \multicolumn{4}{|c|}{ BEKK } & \multicolumn{3}{|c|}{$\mathrm{CCC}$} & \multicolumn{6}{|c|}{ DCC } & \multicolumn{3}{|c|}{ VARMA-CCC } & \multicolumn{4}{|c|}{ VARMA-DCC } \\
\hline & Elef & Oilf & Gasf & Coalf & Elef & Oilf & Gasf & $\begin{array}{c}\text { CoalMS } \\
\text { Userf }\end{array}$ & Elef & Oilf & Gasf & Coalf & Elef & Oilf & Gasf & Coalf & Elef & Oilf & Gasf & Coalf \\
\hline ARCH-LM & 0.877 & 0.930 & 0.256 & 0.404 & 0.961 & 0.998 & 0.310 & 0.523 & 0.865 & 0.840 & 0.330 & 0.572 & 0.792 & 1.205 & 0.472 & 0.313 & 1.151 & 1.124 & 0.665 & 0.533 \\
\hline$Q$-stat. & 13.267 & 15.140 & 18.220 & 19.335 & 12.676 & 14.981 & 19.499 & 19.792 & 12.722 & 14.519 & 17.018 & 19.6641 & 13.9031 & 16.4241 & 19.118 & 19.015 & 12.803 & 15.832 & 19.067 & 19.009 \\
\hline$Q^{2}$-stat. & 3.169 & 6.770 & 7.161 & 10.322 & 4.164 & 5.260 & 9.330 & 8.740 & 4.019 & 5.126 & 6.128 & 9.977 & 4.279 & 6.199 & 8.073 & 9.653 & 3.925 & 6.635 & 7.094 & 8.039 \\
\hline
\end{tabular}




\section{Conclusions}

Previous academic studies have shown that the electricity, oil, natural gas, and coal markets are characterized by high volatility and that they have become more interrelated. Therefore, analyzing the co-movement between these markets as well as their volatility spillovers is very important for investors, traders, and government agencies concerned with the energy markets.

This study has investigated and examined the conditional correlations and volatility spillovers among electricity, oil, natural gas, and coal future price returns, by using the five multivariate symmetric GARCH and asymmetric GARCH models: the BEKK model of Engle and Kroner (1995), the CCC model of Bollerslev (1990), the DCC model of Engle (2002), the VARMA-GARCH model of Ling and McAleer (2003), and the VARMA-AGARCH model of McAleer et al. (2008). We employ a sample size of 2660 observations from March 22, 2004 to May 29, 2014. The empirical results show that these models do capture the dynamic structure of the return interactions and volatility spillovers and display statistical significance for own past mean and volatility short-and long-run persistence effects, while there are just a few cross-market effects for each model.

\section{References}

Bollerslev, T. (1986). Generalized autoregressive conditional heteroskedasticity. Journal of Econometrics, 31, 307-327. http://dx.doi.org/ 10.1016/0304-4076(86)90063-1

Bollerslev, T. (1990). Modeling the coherence in short-run nominal exchange rate: A multivariate generalized ARCH approach. The Review of Economics and Statistics, 72, 498-505.http://dx.doi.org/10.2307/2109358

Cappiello, L., McAleer, M., \& Tansuchat, R. (2003). Asymmetric dynamics in the correlations of global equity and bond returns. European Central Bank working paper no. 204.

Chang, C. L., \& McAleer et al. (2013). Ranking journal quality by harmonic mean of ranks: An application to ISI statistics \& probability. Statistica Neerlandica, 67, 27-53.

Chang, C. L., McAleer, M., \& Tansuchat, R. (2009). Modeling conditional correlations for risk diversification in crude oil markets. Journal of Energy Markets, 2, 29-51. http://dx.doi.org/10.2139/ssrn.1401331

Chang, C. L., McAleer, M., \& Tansuchat, R. (2010). Analyzing and forecasting volatility spillovers, asymmetrics and hedging in major oil markets. Energy Economics. http://dx.doi.org/ 10.1016/j.eneco.2010.04.014

Chang, C. L., McAleer, M., \& Tansuchat, R. (2011). Crude oil hedging strategies using dynamic multivariate GARCH. Energy Economics, 33, 912-923. http://dx.doi.org/10.101016/j.ececo.2011.01.009

Efimova, O., \& Serletis, A. (2014). Energy markets volatility modeling using GARCH. Department of Economics, University of Calgary, working paper, pp. 214-39.

Emery, G. W., \& Liu, Q. (2002). An analysis of the relationship between electricity and natural gas future prices. Journal of Future Markets, 22, 95-122.http://dx.doi.org/10.1002/fut.2209

Engle, R. (2002). Dynamic conditional correlation: A simple class of multivariate generalized autoregressive conditional heteroskedasticity models. Journal of Business and Economic Statistics, 20, 339-350. http://dx.doi.org/ 10.1198/073500102288618487

Engle, R. F., \& Kroner, K. F. (1995). Multivariate simultaneous generalized ARCH. Econometric Theory, 11, 122-150. http://dx.doi.org/10.1017/S0266466600009063

Ewing, B. T., Malik, F., \& Ozfidan, O. (2002). Volatility transmission in the oil and natural gas markets. Energy Economics, 24, 525-538. http://dx.doi.org/10.1016/S0140-9883(02)00060-9

Furio, D., \& Chulia, H. (2012). Volatility transmission in the oil and natural gas markets. Energy Economics, 24 , 525-538. http://dx.doi.org/10.1016/S0140-9883(02)00060-9

Gallaghar, L. A., \& Twomey, C. E. (1998). Identifying the source of mean and volatility spillovers in Irish equities: A multivariate GARCH analysis. Economic and Social Review, 29, 341-356. http://dx.doi.org/10.1080/13504850410001674830

Glosten, L., Jagannathan, R., \& Runkle, D. (1992). On the relation between the expected value and volatility of nominal excess return on stocks. Journal of Finance, 46, 1779-1801. http://dx.doi.org/10.1111/j.1540-6261.1993.tb05128.x

Guesmi, K., \& Fattoum, S. (2014). Return and volatility transmission between oil exporting and oil-importing countries. Economic Modeling, 38, 305-310.

Kroner, K., \& Ng, V. (1998). Modeling asymmetric commovements of nonstationary ARMA models with 
GARCH errors. Annals of Statistics, 31, 642-674. http://dx.doi.org/ 10.1002/9781118272039.

Lanza, A., Manera, M., \& McAleer, M. (2006). Modeling dynamic conditional correlations in WTI oil forward and future returns. Finance Research Letter, 3, 114-132.

Lin, S., \& Tamvakis, M. (2001). Spillover effects in energy future market. Energy Economics, 23, 43-56. http://dx.doi.org/10.1016/S0140-9883(00)00051-7

Ling, S., \& McAleer, M. (2003). Asymptotic theory for a vector ARMA-GARCH model. Econometric Theory, 19, 278-308. http://dx.doi.org/10.1017/S0266466603192092

Mamera, M., McAleer, M., \& Grasso, M. (n. d.). Modeling time-varying conditional correlations in the volatility of Tapis oil spot and forward returns. Applied Financial Economics, 16, 525-533. http://dx.doi.org/10.1080/09603100500426465

McAleer, M., Hoti, S., \& Chan, F. (2009). Structure and asymptotic theory for multivariate asymmetric conditional volatility. Econometric Reviews, 28, 422-440. http://dx.doi.org/10.1080/07474930802467217

Mjelde, J. W., \& Bessler, D. H. (n. d.). Market integration among electricity markets and their major fuel source markets. Energy Economics, 31, 482-491. http://dx.doi.org/10.1016/j.eneco.2009.02.002

Mohanmadi, H. (2009). Electricity prices and fuel costs: Long-run relations and short-run dynamics. Energy Economics, 31, 503-509. http://dx.doi.org /10.1016/j.eneco.2009.02001

Munoz, M. P., \& Dickey, D. A. (2009). Are electricity prices affected by the US dollar to Euro exchange rate? The Spanish case. Energy Economics, 31, 857-866. http://dx.doi.org/doi.10.1016/j.eneco.2009.05.011

Savva, C., Osbor, S. D. R., \& Gill, L. (2005). Spillovers and correlations between US and major European markets: The role of Euro. Centre for Growth and Business Cycle Research Discussion Paper. 064

Serletis, A., \& Shahmoradi, A. (2006). The demand for electricity in Pakistan. OPEC Review Paper, 30, 19-26.

Wong, A. S. K., \& Vlaar, P. J. G. (2003). Modeling time-varying correlations of finance markets. Research Memorandum W08E no. 739, De Nederlanscthe Bank.

\section{Copyrights}

Copyright for this article is retained by the author(s), with first publication rights granted to the journal.

This is an open-access article distributed under the terms and conditions of the Creative Commons Attribution license (http://creativecommons.org/licenses/by/3.0/). 